\title{
Hamid Reza Karami, Mohammad Hasan Talebian. « Modiriyat āb mantagheh Pasargades dar doreh Hakhāmaneshi / Water control system of Pasargad during Achaemenid period »
}

\section{Kourosh Mohammadkhani}

\section{OpenEdition}

\section{Journals}

Édition électronique

URL : http://journals.openedition.org/abstractairanica/45581

DOI : $10.4000 /$ abstractairanica. 45581

ISBN : 1961-960X

ISSN : 1961-960X

Éditeur :

CNRS (UMR 7528 Mondes iraniens et indiens), Éditions de l'IFRI

\section{Référence électronique}

Kourosh Mohammadkhani, « Hamid Reza Karami, Mohammad Hasan Talebian. « Modiriyat āb mantagheh Pasargades dar doreh Hakhāmaneshi / Water control system of Pasargad during Achaemenid period » », Abstracta Iranica [En ligne], Volume 37-38-39 | 2018, document 52, mis en ligne le 30 décembre 2018, consulté le 26 septembre 2020. URL : http://journals.openedition.org/ abstractairanica/45581; DOI : https://doi.org/10.4000/abstractairanica.45581

Ce document a été généré automatiquement le 26 septembre 2020.

Tous droits réservés 


\title{
Hamid Reza Karami,
} Mohammad Hasan Talebian. « Modiriyat àb mantagheh Pasargades dar doreh Hakhāmaneshi / Water control system of Pasargad during Achaemenid period»

\author{
Kourosh Mohammadkhani
}

\section{RÉFÉRENCE}

Hamid Reza Karami, Mohammad Hasan Talebian. « Modiriyat āb mantagheh Pasargades dar doreh Hakhāmaneshi / Water control system of Pasargad during Achaemenid period ", Pazhjuheshhāy-e Bāstānshenāsi Modares (Modares Archaeological Research), vols. 5 \& 6, no. $10 \& 11,2014$ [2015], p. 216-242.

1 Dans le cadre du Centre de Recherche de Pasargades, et avec son soutien, plusieurs études ont été entreprises ces dernières années dans la région de Pasargades, donnant lieu à des mémoires de Master en archéologie. Cette étude résume l'un d'eux (par H.R K) sur la gestion de l'eau dans la plaine de Pasargades, à partir de l'étude des photos aériennes, de la prospection pédestre et de l'analyse des études antérieures sur l'hydraulique dans cette région. Les auteurs décrivent 7 barrages et digues dans le plaine de Morghab/Pasargades et quelques canaux achéménides. Ils pensent que la fonction de ces ouvrages étaient destinées au contrôle des inondations saisonnières, à l'alimentation en eau du site de Pasargades et au stockage de l'eau pour l'irrigation des 
terres agricoles et des jardins. Pour la datation; les auteurs utilisent les résultats d'analyse de la mission franco-iranienne sur le barrage de Shahidabad/Tang-e Hana 1, ainsi que la mise en œuvre d'une maçonnerie de pierre de type achéménide sur quelques-uns d'entre eux, enfin la présence de cairns construits sur quelques barrages à l'époque post-achéménide, donnant un terminus ante quem à leur utilisation. Cette étude est aiunsi dans le cadre des recherches conduites à Pasargades, en particulier par la mission irano-française.

\section{AUTEURS}

\section{KOUROSH MOHAMMADKHANI}

Université Shahid Beheshti, Téhéran 